\title{
ANALYSIS FOR THE EFFECT OF IMPLANT POSITION AND DENTURE BASE MATERIALS ON STRESS DISTRIBUTION IN SINGLE IMPLANT SUPPORTED MANDIBULAR OVERDENTURE (3D FINITE ELEMENT STUDY)
}

\author{
Ahmed A. Elwahed Shaaban*, M. Mohamed Ammar** and Ahmed I. Mahrous***
}

\begin{abstract}
Purpose: The purpose of this finite element analysis study was to evaluate the effect of single implant position (central, canine) and denture base materials (conventional acrylic resin, glass fiber reinforced acrylic resin) on stress distribution in single implant supported mandibular overdenture.

Materials and methods: Two 3 dimensional finite element models of mandibular overdenture supported by a single implant were designed in solid works 2015 software; model I a single implant in central region with conventional acrylic resin denture base, model I b single implant in central region with glass fiber reinforced acrylic resin denture base, model II a single implant in canine region with conventional acrylic resin denture base, model II b single implant in canine region with glass fiber reinforced acrylic resin denture base. A $300 \mathrm{~N}$ vertical and A $300 \mathrm{~N}$ oblique unilateral loads applied at $1^{\text {st }}$ premolar, $2^{\text {nd }}$ premolar and $1^{\text {st }}$ molar areas were applied. Maximum and minimum loads were calculated.
\end{abstract}

Results: Under vertical loading, the maximum stresses in the glass fiber reinforced acrylic denture base half that of conventional one in central position while in canine position nearly $8 \%$ increase in the stresses. Under oblique loading, the maximum stresses in the denture base show no significant difference in the 2 models.

Conclusion: These results should only be used for comparative purposes between the two denture bases and cannot be viewed as a substitute for further clinical investigation.

Conclusion: These resuIts shouId onIy be used for comparative purposes between the two denture bases and cannot be viewed as a substitute for further clinical investigation.

* Lecturer of Prosthodontics, Faculty of Oral \& Dental Medicine, Future University

** Associate Professor of Prosthodontics, Faculty of dentistry, Al-Azhar University, Assiut branch.

*** Associate Professor of Prosthodontics, Faculty of dentistry October 6th University, Egypt 


\section{INTRODUCTION}

Fabrication of a complete mandibular denture that offers patient comfort, function and esthetic harmony along with stability and retention remains one of the most challenging procedures in dental practice. ${ }^{(1)}$ The mandibular implant overdenture as a treatment option for edentulous mandible this help overcoming problems of conventional denture ${ }^{(8)}$ Overdenture provide edentulous patients with a higher quality of life due to their superior retention and stability, improved function and esthetics and reduced alveolar ridge resorption. improve the patient's inability to chew and speak . More recently, the use of OD for the treatment of the edentulous patient has been considered as the first choice treatment for the edentulous mandible. ${ }^{(2)}$ The mandibular overdenture retained by two implants has been recommended as the minimum standard of care for the edentulous mandible. However, in recent years, the single implant mandibular overdenture has been proposed as an alternative to more complex overdenture designs. ${ }^{(2)}$ It was stated that mandibular overdenture retained only by single implant, do not produce damaging strain concentration on bone around the implant and is considered a cost effective treatment modality. ${ }^{(3)}$ The preferred site in single implant overdenture for implant placement biologically is the anterior region of the mandible as thicker cortical bone, lowered surgery risk by avoiding the inferior alveolar nerve and blood vessels and a larger tissue-supporting area to prevent over loading on implant. ${ }^{(4)} \mathrm{An}$ ideal denture base material should have adequate mechanical and physical properties, besides biocompatibility, and aesthetics. Polymethyl methacrylate (PMMA) is frequently used to fabricate denture bases due to its various advantages, including low cost, biocompatibility, ease of processing, stability in the oral environment, and acceptable aesthetics. Several studies have been conducted with the goal of enhancing the properties of PMMA by using different curing methods and/or incorporating fillers in its composition. Addition of fillers and fibers to PMMA is a commonly used method to improve both its physical and mechanical properties. ${ }^{(5)}$ FEA is a method used to provide an answer to a complex mechanical problem by dividing the main domain into group of smaller elements. Answering of these small elements provide a solution for the main problem. ${ }^{(6)}$ Finite element analysis (FEA) has several advantages over other methods, including precise modeling of complex geometries, ability to investigate the internal state of stress and easy model simulation. ${ }^{(7)}$ Therefore the purpose of this in vitro study was to evaluate, through the FEA, the effect of implant position and framework materials on stress distribution in single implant supported mandibular overdenture.

\section{MATERIALS AND METHODS}

In this study a 3D model simulating an edentulous mandible of a 65 years old patient with well develloped ridge was constructed using CT scan by mimics 10.01 software programe (fig.1). The mandibular overdenture was supported by single implant with ball and socket attachment and two types of denture base were used conventional acrylic resin denture base and reinforced acrylic resin by glass fiber denture base.

The model was modified by Solidworks 2015 software to obtain mandibular structures (compact bone, spongy bone and mucosa). Mandibular overdenture supported by single implant was drawn and integrated to the original model. The model was duplicated into 2 identical models except for the position of the dental implant and type of denture base.

- Model Ia the implant at the central incisor region with acrylic denture base.

- Model Ib the implant at the central incisor region with glass fiber reinforced acrylic denture base.

- Model IIa the implant at the canine region with acrylic denture base. 


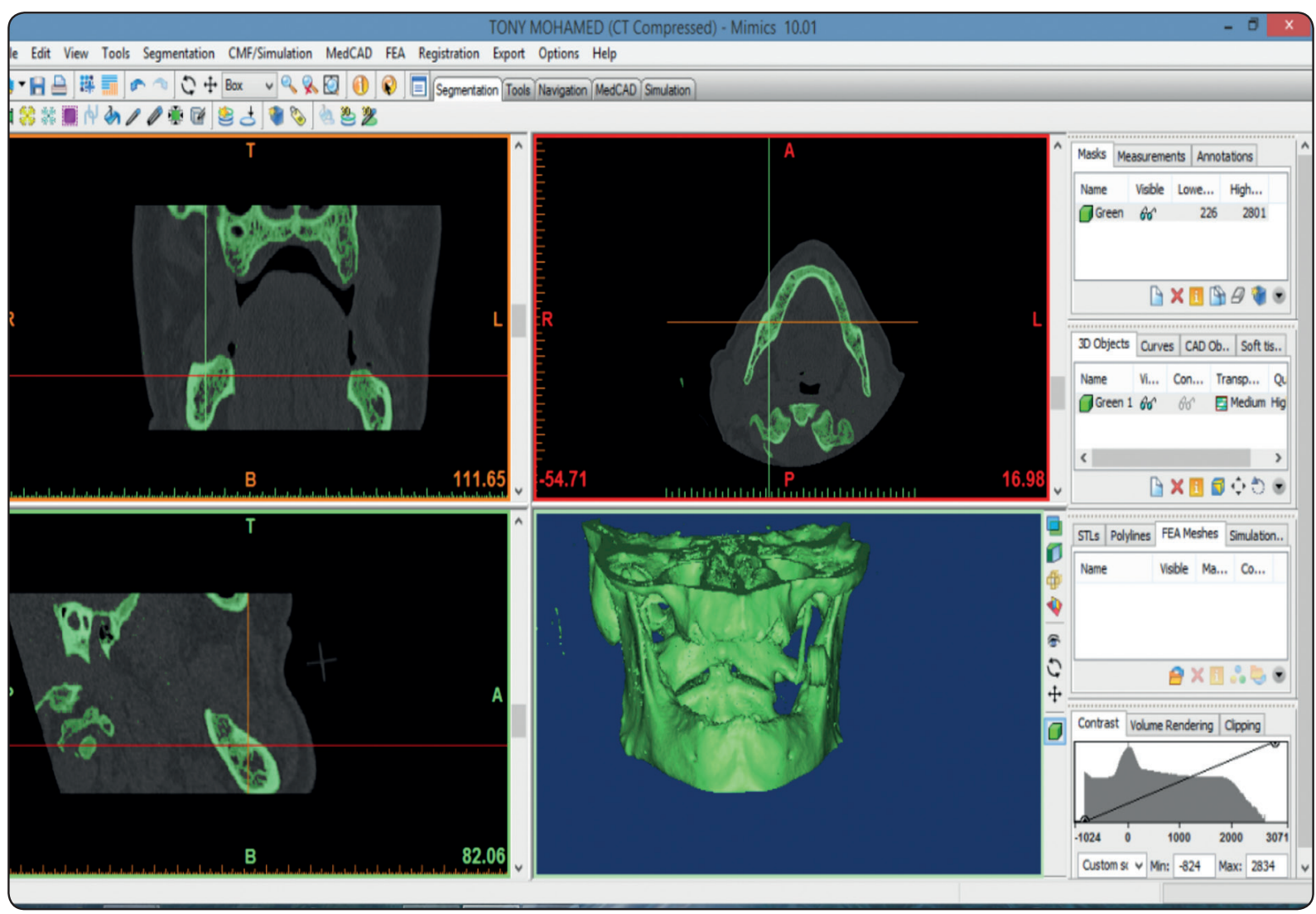

Fig. (1) Calculating 3d model of the mandible

- Model IIb the implant at the canine region with glass fiber reinforced acrylic denture base.

Subtraction was made to all drawn component except one component leaved as a reference point by which assembly could be done. This step was repeated for each component independently. All components which are in contact with their mirror structures were given the same property and were combined to each other e.g.: Compact bone, mucosa and denture base with their mirror structures.

The constructed components were assembled together to form the two models. The technique of model assembly was done by the mating function. The mating function creates one or more geometrical relationship between different components that will facilitates assembly.
The properties of materials, elements and structures were entered into the program. The modulus of elasticity and Poisson's ratio of the used materials were listed (table 1). All material in this study considered homogenous, isotropic and linearly elastic.

Two types of loads were applied to the overdenture in each model to simulate functional loading, vertical and inclined distributed loads on the first premolar, second premolar and first molar of the inserted implant site. Stresses were measured using finite element program (Solidworks 2015 software) and the differences in stress distribution under vertical and oblique load were collected. 
TABLE (1) The modulus of elasticity and Poisson's ratio of the used materials

\begin{tabular}{|c|c|c|c|}
\hline Material/ Components & Elastic modulus Mpa & Poisson's ratio Mpa & Reference \\
\hline Acrylic Resin/ denture bases\& artificial teeth & 2700 & 0.35 & \multirow{5}{*}{ (8) } \\
\hline Compact Bone & 13700 & 0.3 & \\
\hline Cancellous bone for both sides & 1370 & 0.3 & \\
\hline Soft tissue / Mucosa & 1 & 0.37 & \\
\hline Ti-6Al-4V/Implants & 135000 & 0.3 & \\
\hline Nylon / Nylon caps & 2400 & 0.39 & (9) \\
\hline Cr-Co alloy/ Metal housing & 218000 & 0.33 & $(10)$ \\
\hline Glass fiber & 3500 & 0.3 & (11) \\
\hline
\end{tabular}

\section{RESULTS}

The results were estimated by Von Misses stress. The chart was modified and the higher limit was made $5 \mathrm{Mpa}$ to allow proper detection of stresses (fig. 2). The results were collected under two loads; vertical, and oblique loads, in two positions central, and canine under two denture base materials; conventional acrylic resin denture base, and glass fiber reinforced acrylic resin denture base. The results revealed that: Under vertical loading, the maximum stresses in the glass fiber reinforced acrylic denture base half that of acrylic one in central position while in canine position nearly $8 \%$ increase in the stresses. Under oblique loading, the maximum stresses in the denture base show no significant difference in the 2 models (fig.3), (table 2). In model Ia the maximum stresses in compact bone detected away from implant site, the maximum force under vertical load in central position with acrylic denture base half of maximum load under the oblique one, the stresses in the implant started at implant abutment and gradually increased to reach maximum values at area of first contact between implant and bone. Gradual decrease of stresses was detected below this area till apical part of the implant (fig. 4). In model Ib the stresses in compact bone detected away from implant site and homogenous distributed with no area of stress concentration under vertical load, the stresses in the implant no difference as in model Ia. In model IIa the stresses in compact bone detected at the crestal bone at implant site under vertical load and detected apicobuccal to the implant and at the crestal bone under oblique load. The Minimum stresses in the implant were detected in abutment and increased to reach maximum values at the beginning of implant serrations under vertical load and coronal to them under oblique load. Gradual decrease in stresses was detected apical to area of maximum stresses till the apical part of implant. Maximum stresses under oblique load were more than a double of that under vertical load. In model IIb the stresses in compact bone Stresses detected in crestal bone at implant site under vertical load. Stresses detected apico-buccal to the implant and at the crestal bone under oblique load. The stresses in the implant; Minimum stresses were detected in abutment and increased to reach maximum values at the beginning of implant serrations under vertical load and coronal to them under oblique load. Gradual decrease in stresses was detected apical to area of maximum stresses till the apical part of implant. Maximum stresses under oblique load were more than a double of that under vertical load. From the previous results; the following structures showed the greatest differences: Stresses under oblique loads were more than under vertical loads and approximately the double. Maxi- 
mum stresses in compact bone of model II were detect at implant site and at the crestal bone while in model I away from implant site. Maximum stresses in acrylic denture bases of model I were double that of glass fiber reinforced acrylic denture base in the same model. Maximum stresses in implant in model I there no significant difference while in mode II under oblique load no difference while under vertical load no significant difference.

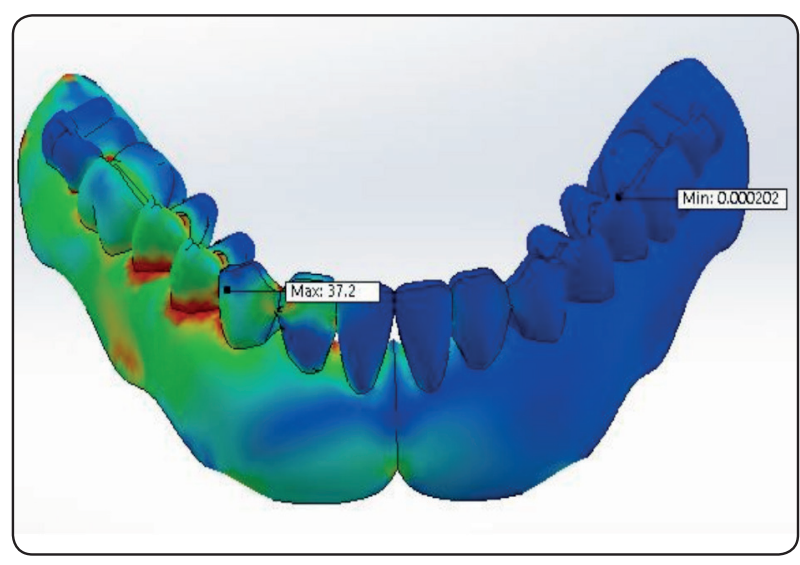

Fig. (3) Stresses in the denture (glass fiberreinforced acrylic denture base) in model.

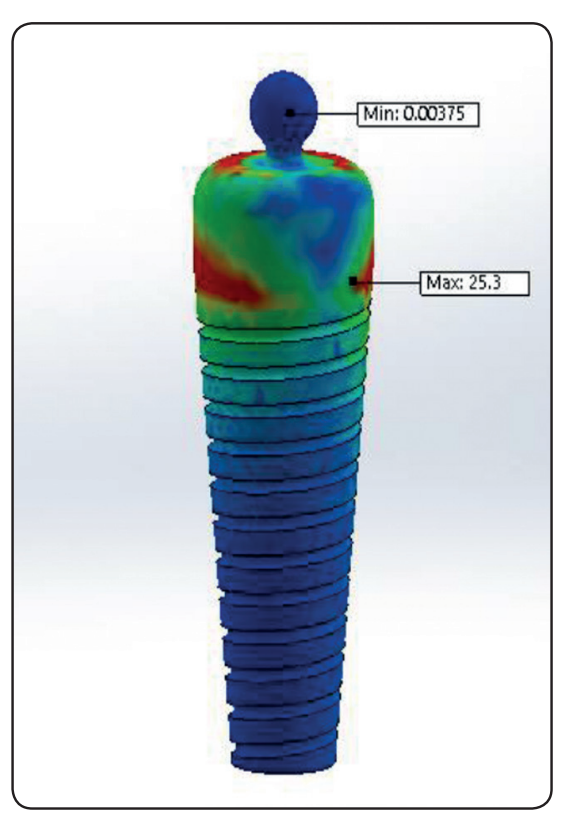

Fig. (4) Stresses in the implant in model Ia under oblique load
Fig. (2) Color chart of Von Misses I b under oblique load.

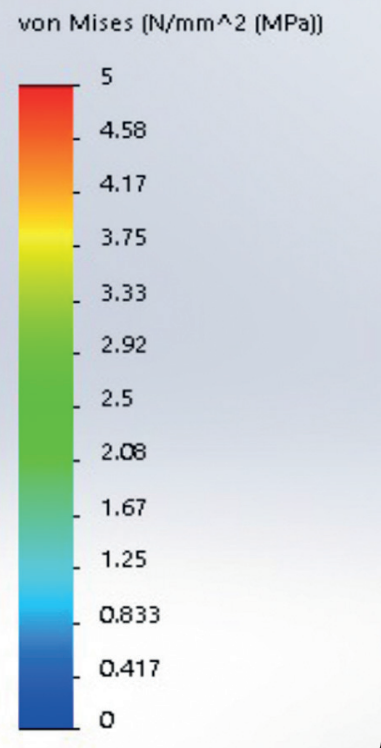

TABLE (3) The stresses in the two denture bases with two position in Mpa.

\begin{tabular}{|c|c|c|c|c|}
\hline \multirow{2}{*}{ Component } & \multicolumn{2}{|c|}{$\begin{array}{c}\text { Vertical load } \\
\text { Mpa }\end{array}$} & \multicolumn{2}{c|}{ Oblique load } \\
& \multicolumn{2}{|c|}{ Mpa } \\
\cline { 2 - 5 } & Min & Max & Min & Max \\
\hline Denture(conventional acrylic resin) in model Ia & 0.000175 & 29.1 & 0.00031 & 35.8 \\
\hline Denture(conventional acrylic resin) in model IIa & 0.000174 & 27.1 & 0.00044 & 49.6 \\
\hline Denture(reinforced by glass fiber) in model Ib & $4.68_{\mathrm{e}} 005$ & 13.4 & 0.000202 & 37.2 \\
\hline Denture(reinforced by glass fiber) in model IIb & 0.000138 & 29.5 & 0.000266 & 50.3 \\
\hline
\end{tabular}




\section{DISCUSSION}

This stress analysis study, 3-D FEA was used to assess stresses induced by different denture base materials with two position of single implant in implant supported overdenture on implant and overdenture supporting structure. The finite element analysis (FEA) is considered the most commonly invitro studies used now when comparing two or more prosthetic design under the same loading conditions. (12) Finite element analysis was proven to be a reliable method that allows researchers to overcome some ethical and methodological limitations. A fact is that the analysis are based on a specific set of input values that are assumed to be average or representative, such as bone dimensions, material properties and specific occlusal loading directions. The single implant is relatively a new approach that reduces time and cost considerably. This treatment option produces a promising solution for complete denture problems, especially in developing countries where the treatment cost is the main challenge for many patients. A computed tomographic image was obtained for an edentulous patient undergoing implant surgery. MIMICS 10.01 software was used in order to enhance the definitions of the obtained model. This software program can differentiate between various anatomical parts based on their radio opacity. The steps of model construction were similar to a previous study Mohsen H, 2016 $6^{(13)}$ The mandible was sketched by solid works 2015 sp0.0 software guided by coronal cut images obtained from MIMICS 10.01 software. Drawing one half of the model and production of the other half by mirror imaging was done to simplify the process of model designing. The thickness of mucosa, spongy and compact bone at different locations were modeled. (8) The implant was drawn simulating one of the commercially available implants, and it placed in central, canine position. In this study all components were substracted from each other leaving one component as reference by which the assembly could be done. To each material, the modulus of elasticity and Poisson's ratio are assigned. All materials in the study were considered to be homogenous, isotropic and linearly elastic. ${ }^{(6)}$ Such an assumption is not real and ignores the anisotropic and nonlinear behavior of the supporting structures. Moreover the response of bone including repair capacity or failure limit as well as ligaments and muscular attachments were not simulated. All these factors would affect complete interpretation of the results. However the comparative nature of the present study "between different implant position, different denture base materials and loading conditions" reduces the significance of the previously mentioned factors.

All components were constructed in a way that assured $100 \%$ contacts along every interface i.e. there were no gaps or interfaces. Absence of gaps between different models components is a prerequisite to avoid any geometrical error in meshing feature. Therefore structures penetrate each other e.g.: bone implant, were given bonded type contact. Whereas the structures not penetrating each other were given" no penetration" type contact. The models were constrained from the bottom surface of the mandible and distal aspect of the condyles by application of fixtures and restraints. These restraints were defined to avoid analysis failure due to rigid body motion. In this way no translation was allowed for these structures in all direction. The biting force is a dynamic cycle that can't be represented on the software, which is considered as an inherent limitation of the finite element analysis. Thus the static loading is considered in this study. ${ }^{(14,15)}$ The load directions used in the present study represent a more realistic condition. Occlusal forces are not always axial and more horizontal, but more likely is oblique in nature as a result of these combinations. Therefore the oblique load application was selected and the vertical was used as a reference. The curvature-based mesh was used for the current study rather than standard mesh, it supports compatible meshing between touching solid faces. It can also check for interference between bodies before meshing. 
The magnitude of von Misses stresses at each element (maximum and minimum) were calculated for each loading condition. The selection between the von Misses stresses and the principal stresses values when calculating stress in the bone is controversial. Researchers who adopted the use of the principal stress suggested that bone is a brittle material and should be described with stress patterns utilized for brittle materials which are the maximum and minimal principal stresses. Other researchers suggested that the Von Misses stress can be also used because the wet bone does not show a brittle behavior. ${ }^{(6)}$ Furthermore, most of the stresses values that occur during occlusal loading are below the yield strength of the material which makes the description brittle or ductile irrelevant. (16) A recent study calculated both von Mises and principal stresses for their models and found that the tendency and percentage of changes were similar for both stresses types. ${ }^{(17)}$ Pattern of load distribution is essentially the same for all models. That is to say, there are certain structures that bear the greatest percentage of stresses. These are compact bone, implant and the denture while other structures such as spongy bone and mucosa shears small amount of stress in all models. This finding is similar to the work of that previous study. ${ }^{(18,19)}$

Maximum stresses in compact bone of model I were located away from implant site, while in model II were located at implant site. This is an indication that implant insertion at the canine region may not be preferred. This stress concentration may be untolerable to the thin remaining bone around implant. This may lead to bone resorption or even implant failure. The cause of such stress concentration may be due to location of the implant at the corner of the ridge where different directions of denture base movement can lead to this stress concentration. Comparing the stresses in implant; the least values were detected in model I. This may be due to the long distance between loading site (1st premolar, 2nd premolar and 1st molar) and implant site (central incisor area). It may also be due to dissipation of stresses over the remaining ridge more properly. Maximum stresses also were detected at crestal bone around the implant in all models. This indicates the importance of ensuring proper bone quantity at this area to withstand the predicted stresses. From the previous results we can recommend that when using single implant to retain mandibular overdenture; selecting the area of central incisor is the best option, taking into consideration the other parameters (bone quantity and quality, implant length and diameter and primary stability). Maximum stresses in different denture bases (acrylic and fiber glass) in model II under vertical load were comparable, with little differences between models, Also the site of maximum stresses was the same (between the 1st and 2nd premolars).

This may be due to the vertical direction of load; which has little damaging effect. While in model I the maximum stresses in the acrylic denture base was double that of fiber glass under vertical load lead to failure in denture base is predicted after few cycles of function. Under oblique loading, which is the case during mastication; maximum stresses in the denture bases were detected at the implant site in model II. This may be due to denture base movement that may tend to pull the implant. So the implant in this case resists denture displacement. Stresses delivered to the denture in model I and model II no comparable difference between 2 denture base in two position. Stresses in spongy bone were less than $3 \mathrm{Mpa}$. This indicates that the compact bone bears the greatest part of stresses. It also emphasizes the importance of compact bone anchorage. Tensile stresses were detected in model I and II in mucosa. Such tensile stresses are probably due to denture base movement toward tissues at the loading side and away from the tissues at the unloaded side, which may exert pull action.

The results of this study may be affected by:

- Considering the compact and cancellous bones as homogenous, isotropic, and linear elastic which doesn't simulate the real situations. 
- The simulated structures were assumed to have $100 \%$ contact without gaps. This assumption is not real and can influence the results.

- The prevention of mandibular translation through restraints may also affect the results.

- Finite element models (FEM) did not include the insertion of the ligaments and muscles of mastication.

- The FEA method also overlooks the stress tolerance level by bone or bone repair capacity.

However, these limitations had no significant influence on comparative study done on duplicated model such as the current study.

\section{REFERANCE}

1. El-Anwar MI, Yousief SA, Soliman TA, et al.,: A finite element study on stress distribution of two different attachment designs under implant supported overdenture. Saudi Dent J. 2015;27(4):201-7.

2. Nogueira TE, Dias DR, Leles CR,: Mandibular complete denture versus single-implant overdenture: a systematic review of patient-reported outcomes. J Oral Rehabil. 2017;44(12):1004-1016.

3. Trakas, Michalakis, Konstantinos DDS, et al.,: Attachment Systems for Implant Retained Overdentures: A Literature Review. Implant Dent J. 2006;15(1):24-34.

4. Van Kampen FMC, van der Bilt A, Cune MS, et al.,: Masticatory function with implant-supported overdentures. J Dent Res. 2004; 83(9):708-11.

5. Mohammed M Gad, Shaimaa M Fouda, Fahad A AlHarbi, et al.,: PMMA denture base material enhancement: a review of fiber, filler, and nanofiller addition. Int $\mathbf{J}$ Nanomedicine. 2017;12:3801-12.

6. Geng JP, Tan KB, Liu GR.: Application of finite element analysis in implant dentistry: a review of the literature. $\mathrm{J}$ Prosthet Dent. 2001 ;85(6):585-98.

7. Chun L., Cheong S., Han J.: Evaluation of design parameters of osseointegrated dental implants using finite element analysis. J. Oral Rehabil. 2002;29:565-574.

8. Daas M, Dubois G, Bonnet AS, et al.,: A complete finite element model of a mandibular implant-retained overdenture with two implants: comparison between rigid and resilient attachment configurations. Med Eng Phys. 2008; 30(2):218-25.

9. Wang HY, Zhang YM, Yao D, Chen JH.: Effects of rigid and non rigid extra coronal attachments on supporting tissues in extension base partial removable dental prostheses: a nonlinear finite element study. J prosthet dent. 2011; 105(5):338-46

10. Aydin C, Cağlar A, Ozen J, et al.,: Effects of mesiodistal inclination of implants on stress distribution in implant supported fixed prostheses. Int J Oral Maxillofac Implants. 2006; 21(1):36-44.

11. Raszewski Z, Nowakowska D: Mechanical Properties of Hot Curing Acrylic Resins after Reinforced with Different Kinds of Fibers. Int Biomed Mat Res J. 2013;1(1):9-13.

12. Guan H, van Staden R, Loo YC, et al.,: Influence of bone and dental implant parameters on stress distribution in the mandible: a finite element study. Int J Oral Maxillofac Implants. 2009; 24(5):866-76

13. Mohsen H.: effect of changing implant position in single implant supported mandibular over denture, 3d finite element study. Minia University 2016

14. Gultekin BA, Gultekin P, Yalcin S.: Application of finite element analysis in implant dentistry: INTECH Open Access Publisher; 2012.

15. Kheidr AA.: Effect of Two Types Of Denture Base Materials on the Stress Distribution in. Implant supported Overdentures. Thesis Submitted to. The Faculty of Oral and Dental Medicine. Cairo University 2012.

16. Fung YC.: Biomechanic: mechanical properties of living tissues.2nd edition. Springer-Verlag, New York, 1993:51018.

17. Wang D, Cheng L, Wang C, et al.,: Biomechanical analysis of rapid maxillary expansion in the UCLP patient. Med Eng Phys 2009; 31(3):409-17.

18. Desai Shrikar R, Shinde Harshada H.: Finite element analysis: basics and its applications in dentistry. Indian $\mathrm{J}$ Dent Sci. 2012; 4(1):60-5.

19. Liu J, Pan S, Dong J, et al.,: Influence of implant number on the biomechanical behaviour of mandibular implantretained/supported overdentures: A three-dimensional finite element analysis. J Dent. 2013;41(3):241-9. 